\title{
The medical treatment of gastric and duodenal ulcer
}

\author{
M. J. S. LANGMAN \\ Member of Scientific Staff, M.R.C. Statistical and Gastroenterological Research Units, \\ University College Hospital, London, W.C. 1
}

THERAPY for gastric and duodenal ulceration has in general been based upon rest, frequent meals, the avoidance of stress and potential irritants such as aspirin and smoking and the initiation of treatment designed to reduce the corrosive quality of the gastric juice. Progress has however been considerably hindered by our poor understanding of causal mechanisms.

Gastric ulcer tends to be associated with acid hyposecretion and some degree of gastritis, while in duodenal ulcer the parietal cell mass is usually large and there is generally a high level of acid output. But it is not known if the gastric acid secretory capacity affects either the short-term results of ulcer treatment or the ultimate prognosis. There is good evidence that genetic factors associated with the ABO blood groups influence the behaviour (Langman \& Doll, 1965) and probably also the incidence (Aird et al., 1954) of gastric and duodenal ulceration. The gastroduodenal mucosa contains substantial quantities of the blood group substances (Szulman, 1960, 1962) and it is tempting to consider that the different ABO blood group substances vary in the protective qualities which they give against ulceration. There is, however, no clear evidence in support of such an effect, which would in any case be likely to be small because the ABO associations are themselves comparatively weak. It is likely that environmental influences are of primary importance in influencing the incidence of ulcer, a view emphasized by the changing ratio of gastric to duodenal ulceration in the last 100 years and by the striking geographical variations in ulcer incidence. There are, however, no clear indications of the basic mechanisms underlying these environmental factors.

Tobacco smoking has been demonstrated on several occasions to be associated with an increased mortality from ulcer but the tendency is probably greater for gastric than duodenal ulcer (Hammond \& Horn, 1958). The latter is the commoner disease and smoking is, therefore, unlikely to be of primary importance in the causation of duodenal ulceration (nor probably indeed in gastric ulceration). In spite of the known association between peptic ulceration and hepatic cirrhosis there is no evidence that moderate alcohol consumption has any real effect upon ulcer incidence or prognosis. Finally no specific dietary item has ever been convincingly shown to be associated with liability to ulceration.

Medical treatment has in the past been largely based upon the results reported by physicians of their clinical experience obtained in uncontrolled trials. Such results are however of little if any value because of the natural tendency for both gastric and duodenal ulcer to pursue a remittent course with occasional exacerbations. The technique of the controlled clinical trial has, particularly in the last 15 years, allowed for more rigorous testing of the remedies usually advocated. Such trials have been of particular value in the study of gastric ulceration where comparative radiological studies can be performed before and after a course of treatment. Duodenal ulcer has been harder to study because clear radiological definition of an ulcer crater in the presence of a deformed duodenal cap can be difficult if not impossible. This problem is of special significance because the duodenal ulcer in the undeformed cap is a comparative rarity. Conclusions from studies of patients with such lesions may have little relevance to the results which might be obtained in individuals with permanent duodenal abnormalities due to scarring.

The value of short-term clinical studies of duodenal ulcer treatment can be increased by adding comparisons of ulcer symptoms during treatment, but symptoms or their absence are not necessarily a true guide to the activity of ulceration. Another approach has been to compare the relapse or complication rates in patients given different treatments after their initial symptoms have settled. This type of study has the disadvantage that treatment may have to be continued for prolonged periods of two or more years if sufficient time is to be allowed for any differences between groups to be observed.

After consideration of these problems it 
becomes clear why progress has not been more rapid in defining the value of specific treatments for gastric or duodenal ulcer.

In theory it would be preferable to consider medical treatment of three types.

(a) Management of acute symptoms.

(b) Treatment designed to heal the ulcer.

(c) Prevention of relapse.

However, the treatments which promote the healing of ulcers are few and none has been definitely shown to prevent relapse. It is therefore preferable to try to define separately the value of each treatment at present available.

\section{General measures}

Bed rest

It is well known that ulcer symptoms remit rapidly when patients are admitted to hospital, and there is evidence that gastric ulcers do in fact heal more readily during inpatient than outpatient care (Doll \& Pygott, 1952). However, there is no good evidence that duodenal ulcers tend to heal during periods of rest, though equally there is none to the contrary.

No satisfactory evidence is available to show whether a period of in-patient treatment effects the later course of the ulcers.

\section{Diet}

In the past it has been conventional to give the ulcer patient a diet graduated from one which consisted mainly of milk and milk-products to a final level where foods were still restricted in type and were usually sieved or mashed. The experimental evidence favouring the use of any such diets is however extremely poor.

Nicol (1939) found that the mean acidity of gastric contents when sampled hourly through a naso-gastric tube was little different in patients taking milk, cream and vegetable puree every $2 \mathrm{hr}$ and in those individuals who took a light diet composed of four main meals and $150 \mathrm{ml}$ of milk at night. By a similar technique Lennard Jones \& Babouris (1965) showed that the $\mathrm{pH}$ of samples of gastric juice collected every hour differed little in patients taking a diet of their own choice and in those taking conventional gastric diets. The only factor which appeared to affect $\mathrm{pH}$ to any marked degree was the timing of meals. A free-choice diet taken at 2-hourly intervals tended to reduce the swings of acidity produced by the same diet given at 4-hourly intervals.

This evidence from sampling studies is supported by the results of controlled clinical trials. There is no evidence that any particular diet will influence the healing rate of gastric ulcer,
(Evans, 1954 ; Doll, Friedlander \& Pygott, 1956 ; Truelove, 1960) and though the evidence is not so satisfactory for duodenal ulcer such studies as have been performed have similarly failed to show any real differences.

Some patients do find however that fried foods cause pain and therefore they are probably best avoided. It also seems sensible to advise against the taking of spirits.

There is no evidence to suggest that, once remission has occurred, any particular food will confer protection against relapse.

\section{Smoking}

Though it is commonly stated that ulcer patients should smoke little if at all there is only scanty evidence to support this view. A higher proportion of smokers than non-smokers has been found in individuals with gastric and with duodenal ulcers than might have been expected from comparable control populations and it has also been shown that cessation of smoking promotes the short-term healing of gastric ulcers (Doll, Jones \& Pygott, 1958). There is no useful evidence about the effect of stopping smoking on the healing of duodenal ulcers nor that smoking increases the chances of relapse of gastric or duodenal ulcers. However, on general clinical grounds it seems reasonable to advise against the habit.

\section{Drugs}

Alkalis

There is considerable disparity between the brief period of minutes in which an alkali will reduce gastric acid and the prolonged period, often of several hours for which symptoms will be relieved.

In vitro tests have shown that sodium bicarbonate, calcium carbonate and magnesium oxide or hydroxide are the most efficient preparations for acid neutralization (Piper \& Fenton, 1964). But there is little evidence to suggest that any preparation even when given in large doses affects ulcer healing. Price \& Sanderson (1956) estimated that $60 \mathrm{~g}$ of sodium bicarbonate, given daily by intra-gastric drip, would be needed to keep the $\mathrm{pH}$ of the stomach contents above 4.0 in those with gastric ulcer: clearly in duodenal ulcer even larger amounts would be required. The value of a milk-alkali drip in healing duodenal ulcer rather than relieving symptoms has never been proved and such treatment has been demonstrated to be of little, if any, value in gastric ulceration.

The intensive use of alkalis in the treatment of duodenal ulcer needs more rigorous testing, but 
it may well be that treatment would be limited by the known side-effects of the therapy. Magnesium salts tend to cause diarrhoea, calcium carbonate and sodium bicarbonate can induce alkalosis, and calcium salts can also cause hypercalcaemia.

It has been suggested recently that the concurrent administration of anticholinergic drugs can reduce the need for alkalis (Fordtran \& Collyns, 1966) but the clinical value of this treatment remains unproved.

\section{Anticholinergic drugs}

Anticholinergic agents of all types will undoubtedly reduce the amount of acid secreted by as much as $50 \%$ but this impressive difference is much smaller when converted into terms of $\mathrm{pH}$ units. Therefore, alterations of peptic activity may be considerably less than the initial results in terms of volume of secretion might imply.

The side-effects of atropine-like drugs may be less in the newer preparations such as poldine, propanthalene and isopropamide but they are by no means insignificant. Anticholinergic drugs can be useful in the relief of acute ulcer symptoms but it is not yet entirely clear whether they improve the healing rate or reduce the relapse rate of duodenal ulcer. There is some evidence to suggest that they are of little value (Lennard Jones, 1961 ; Melrose \& Pinkerton, 1961) but the reason for the disappointing findings may be that anticholinergic drugs to be effective must be given in the maximum doses which can be tolerated without side-effects. Sun (1964) has claimed that the duodenal ulcer relapse-rate can be reduced if glycopyrrolate is given in the maximum tolerated doses, a similar conclusion being reached by Hunt \& Wales (1966). In a smaller group of subjects given poldine. Confirmation, or otherwise, of these results is clearly needed for it is obviously undesirable that large numbers of duodenal ulcer patients be given high doses of anticholinergic drugs for long periods unless unequivocal evidence of benefit can be obtained.

\section{Sedatives}

Sedative drugs such as amytal or phenobarbitone can often be of great value in relieving the symptoms of selected ulcer patients. There is, however, no evidence that such treatment is any more effective than dummy tablets in inducing ulcer healing (Doll \& Pygott, 1952; Truelove, 1960).

\section{Carbenoxolone sodium}

It is now well established (Doll et al., 1962 ; Doll, Hill \& Hutton, 1965, Horwich \& Galloway, 1965) that carbenoxolone sodium will promote the healing of gastric ulcers. The drug is of particular value in treating patients while ambulant and at work, but unfortunately its use is frequently attended by fluid retention which can be sufficiently severe to cause congestive cardiac failure. It should, therefore, not be given to individuals with significant heart or lung disease unless they are carefully supervised.

In previous trials at the Central Middlesex Hospital fluid retention was noted to occur in a high proportion of patients treated with $100 \mathrm{mg}$ three times daily of carbenoxolone for 4 weeks. Further studies have therefore been carried out (Doll, Langman \& Shawdon, 1968) comparing the effects of low (150 mg daily) and high (300 mg daily) doses of carbenoxolone in combination with different diuretic treatments. Each main group was subdivided into two, one subgroup of patients being given a thiazide diuretic and potassium supplement only if clinically indicated by signs of developing fluid retention whilst the other was given spironolactone $25 \mathrm{mg}$ four times a day from the start of carbenoxolone treatment. The results give in Table 1 show that there was a marked difference in the degree of healing, as measured by the average reduction in size of the ulcer niche between the various groups.

\section{TABLE 1}

Change in gastric ulcer size following 4 weeks treatment with high and low doses of carbenoxolone in combination with two different diuretic regimes

\begin{tabular}{lcc}
\hline \multicolumn{1}{c}{ Treatment combination } & $\begin{array}{c}\text { No. of } \\
\text { patients } \\
\text { treated }\end{array}$ & $\begin{array}{c}\text { Mean reduc- } \\
\text { tion in ulcer } \\
\text { size (\%) }\end{array}$ \\
\hline $\begin{array}{l}\text { Carbenoxolone } 300 \mathrm{mg} \text { daily* } \\
\text { with spironolactone (aldactone A) }\end{array}$ & 17 & $47 \cdot 6$ \\
$\begin{array}{l}100 \mathrm{mg} \text { daily throughout } \\
\text { Carbenoxolone } 300 \mathrm{mg} \text { daily* } \\
\text { with a thiazide diuretic if clinically } \\
\text { indicated }\end{array}$ & 17 & $90 \cdot 0$ \\
$\begin{array}{l}\text { Carbenoxolone } 150 \mathrm{mg} \text { daily with } \\
\text { spironolactone } 100 \mathrm{mg} \text { daily } \\
\text { throughout }\end{array}$ & 11 & $28 \cdot 1$ \\
$\begin{array}{l}\text { Carbenoxolone } 150 \mathrm{mg} \text { daily with } \\
\text { a thiazide diuretic if clinically } \\
\text { indicated }\end{array}$ & 11 & $50 \cdot 4$ \\
\hline
\end{tabular}

*225 mg daily in patients under 60 years of age.

Carbenoxolone in a dose of $300 \mathrm{mg}$ daily was markedly superior to $150 \mathrm{mg}$ daily, but within each group there was also a clear difference according to the diuretic regime. Those patients given spironolactone throughout showed less ulcer healing than those given thiazide when needed. Only one patient given spironolactone 
developed clinical evidence of fluid retention, whereas fluid retention developed in a high proportion of those who were not given a thiazide diuretic until there was clinical evidence of the side effect.

These results at first sight suggest that the fluid retention is in some way a necessary concomitant of ulcer healing. It should be noted however that further analysis of the data obtained in patients treated with drug combinations which did not include spironolactone showed that the healing response was comparable in patients who did and who did not need a thiazide diuretic. It would seem, therefore, that the aldosterone antagonist has some kind of blocking action on the mechanisms responsible for gastric ulcer healing. Such an action might be related in some way to the known effects of spironolactone on potassium transport in the gut (Elmslie, Mulholland \& Shields, 1966).

TABLE 2

Relapse rate at 1 year in patients whose gastric ulcers healed after 4 weeks' treatment with carbenoxolone or dummy tablets (given during treatment trials of Doll et al., 1962, 1965)

\begin{tabular}{lcc}
\hline & $\begin{array}{c}\text { Carbeno- } \\
\text { oxolone }\end{array}$ & $\begin{array}{c}\text { Dummy } \\
\text { tablets }\end{array}$ \\
\hline Total no. of patients treated & 54 & 42 \\
$\begin{array}{l}\text { Ulcers healed after 4 weeks' } \\
\text { treatment }\end{array}$ & 22 & 7 \\
$\begin{array}{l}\text { No. of these patients with ulcers } \\
\text { still healed radiologically at 1 year }\end{array}$ & 14 & 4 \\
$\begin{array}{l}\text { Relapsed radiologically within } \\
\text { 1 year }\end{array}$ & $6 *$ & 3 \\
\hline
\end{tabular}

* Radiological studies were only possible in the two remaining patients after a period greater than 1 year-both had relapsed.

Our own results would suggest that once a gastric ulcer has healed the benefit may be in part maintained for at least a year. Table 2 shows that in patients treated in the two early studies at Central Middlesex Hospital twentynine ulcers healed during the 1 month treatment period, in the control and in the dummy treatment groups. At 1 year a high proportion of these remained healed irrespective of the initial therapy, no further treatment having been given.

We have also carried out a small maintenance trial of carbenoxolone $25 \mathrm{mg}$ b.d. for 6 months in twenty-eight patients whose gastric ulcers healed during an initial treatment period. Though no side-effects were observed the clinical results showed so little difference between the test and control groups that the trial was discontinued.

There is no evidence to suggest that the carben- oxolone in its present tablet form is of any value in treating duodenal ulceration, but clinical trials of a new and potentially interesting variant are at present in progress, and promising results have been reported in one (Craig et al., 1967).

\section{Oestrogens}

The observation that oestrogens would inhibit experimental ulceration in animals, and the known excess of men over women amongst duodenal ulcer patients led Truelove (1960) to carry cै out a controlled trial of stilboestrol $0.5 \mathrm{mg}$ b.d. $\vec{\circ}$ in men with duodenal ulcer. The results suggested that a high proportion of duodenal ulcers healed on the active treatment in men with less than 10 years' history of symptoms. Unfortunately the treatment was attended by a high incicidence of side-effects, namely mastitis and impotence. The findings have not been re- or examined by other workers, but in a recent trial at the Central Middlesex Hospital carried out $\mathcal{C}$ with oestriol no significant benefit was found in $\mathrm{O}$ the test as compared with the control group.

\section{Antipepsins}

Certain heparin-like substances possess considerable antipeptic activity when given by mouth, Unfortunately those preparations at presen available seem to be largely bound and inactis. ated by food. Until this disadvantage can be surmounted they are unlikely to be of clinical value.

\section{Conclusions}

Only three measures, bed rest, stopping smoking and the administration of carbenoxolone seem to accelerate the healing rate of gastric ulcer and none is definitely known which will prevent relapse.

The treatment of duodenal ulcer has, due to difficulty of satisfactorily assessing the results of controlled clinical trials, continued to be based largely on the neutralization or reduction of $\delta$ gastric acid secretion. No clear evidence is yet $₹$ available that these or any other measures will $\frac{\mathrm{g}}{\mathrm{T}}$ promote ulcer healing. An exciting prospect for $D$ the future however has been the synthesis of a compound possessing antigastrin activity (SC15396) (Cook \& Bianchi, 1967). If this should or prove to be active when taken by mouth and $\mathcal{N}$ relatively non-toxic it could supply a physiological answer to the treatment of duodenal ulcer.

\section{References}

Aird, I., Bentall, H.H., Mehigan, J.A. \& Roberts, J.A.F. (1954). The blood groups in relation to peptic ulceration $\square$ and carcinoma of colon, rectum, breast and bronchus. Brit. med. J. ii, 315. 
CoOK, D.L. \& BIANCHI, R.G. (1967) SC-15396: A new antiulcer compound possessing anti-gastrin activity. Life Sciences, 6, 1381.

Craig, O., Hunt, T.C., Kimerling, J.J. \& Parke, D.V. (1967) Carbenoxolone in the treatment of duodenal ulcer. Practitioner, 199, 109.

Doll, R., Friedlander, H. \& Pygott, F. (1956) Dietetic treatment of peptic ulcer. Lancet, ii, 5 .

Doll, R., Hill, I.D. \& Hutton, C.F. (1965) Treatment of gastric ulcer with carbenoxolone sodium and oestrogens. Gut, 6, 19.

Doll, R., Hill, I.D., Hutton, C.F. \& Underwood, D.J. (1962) Clinical trial of a triterpenoid liquorice compound in gastric and duodenal ulcer. Lancet, ii, 793.

Doll, R., Jones, F.A. \& Pygott, F. (1958) Effect of smoking on the production and maintenance of gastric and duodenal ulcers. Lancet, i, 657.

Doll, R., Langman, M.J.S. \& Shawdon, H.H. (1968) Treatmnte of gastric ulcer with carbenoxolone, antagonistic effect of spironolactone. Gut, 9, 42 .

DolL, R. \& PygotT, F. (1952) Factors influencing the rate of healing of gastric ulcers. Lancet, $\mathbf{i}, 171$.

Elmslie, R.G., Mulholland, A.T. \& Shields, R. (1966) Blocking by spironolactone (SC 9420) of the action of aldosterone upon the intestinal transport of potassium, sodium and water. Gut, 7, 697.

Evans, P.R.C. (1954) Value of strict dieting, drugs, and 'Robaden' in peptic ulceration. Brit. med. J. i, 612.

FordTRAN, J.S. \& CollyNs, J.A.H. (1966) Antacid pharmacology in duodenal ulcer. New Engl. J. Med. 274, 921.

Hammond, E.C. \& HoRN, D. (1958) Smoking and death rates Report on forty-four months of follow-up in 187,783 men. J. Amer. med. Ass., 166, 1159.

HoR WICH, L. \& Galloway, R. (1965) Treatment of gastric ulceration with carbenoxolone sodium. Clinical and radiological evaluation. Brit. med. J. ii, 1274.
Hunt, J.N. \& Wales, R.C. (1966) Progress in patients with peptic ulceration treated for more than five years with poldine including a double-blind study. Brit. med. J. ii, 13.

LANGman, M.J.S. \& Doll, R. (1965) ABO blood group and secretor status in relation to clinical characteristics of peptic ulcers. Gut, 6, 270.

LENNARD JONES, J.E. (1961) Experimental and clinical observations on poldine in treatment of duodenal ulcer. Brit. med. J. 1, 1071.

LENNARD JoNES, J.E. \& Babouris, N. (1965) Effect of different foods on the acidity of the gastric contents in patients with duodenal ulcer. I A comparison between two 'therapeutic' diets and freely-chosen meals. Gut, 6, 113.

Melrose, A.G. \& Pinkerton, I.W. (1961) Clinical evaluation of poldine methosulphate. Brit. med. J. i, 1076.

Nicol, B.M. (1939) Control of gastric acidity in gastric ulcer. Lancet, ii, 881.

Piper, D.W. \& Fenton, B.H. (1964) Antacid therapy of peptic ulcer. II An evaluation of antacids in vitro. Gut, $5,585$.

Price, A.V. \& Sanderson, P.H. (1956) Alkali requirement for continuous neutralization of gastric contents in gastric and duodenal ulcer. Clin. Sci. 15, 285.

SuN, D.C.H. (1964) Long-term anticholinergic therapy for prevention of recurrences in duodenal ulcer. Amer. J. dig. Dis. 9, 706.

Szulman, A.F. (1960) The histologic distribution of blood group substances A and B in man. J. exp. Med. 111, 785.

Szulman, A.F. (1962) The histologic distribution of blood group substances in man as disclosed by immunofluorescence. II. The $\mathbf{H}$ antigen and its relation to $\mathbf{A}$ and $\mathbf{B}$ antigens. J. exp. Med. 115, 977.

Truelove, S.C. (1960) Stilboestrol, phenobarbitone and diet in chronic duodenal ulcer. Brit. med.J. ii, 559. 